\title{
SiM
}

\section{Acquiring Water Services From Northern Everglades Ranchlands}

\author{
Assuring buyers that they get what they paid for
}

\author{
By Leonard Shabman, Sarah Lynch, and Elizabeth H. Boughton
}

\section{On the Ground}

- The Northern Everglades Payment for Environmental Services (NE-PES) Program implemented by the South Florida Water Management District (SFWMD) is a unique example of an operating market-like payment for environmental services program on working ranchlands.

- The SFWMD enters into 10-year contracts to pay ranchers who dedicate parts of their ranch to providing water retention or nutrient removal services.

- NE-PES monitoring procedures were designed to assure that water was managed as agreed to in the contracts and annual payments only were made if contract terms were honored.

- Key challenges to the design of monitoring procedures were that the protocol must 1) satisfy the buyer that they were getting the services they paid for, 2) assure the sellers that the services they provide are being fairly assessed, and 3) be feasible to administer over a large number of ranches in an expansive working agricultural landscape.

Keywords: payment for environmental services, water retention, nutrient removal, monitoring, Northern Everglades.

Rangelands 35(5):88-92

doi: 10.2111/RANGELANDS-D-13-00025.1

(C) 2013 The Society for Range Management

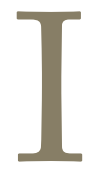
n January of 2011, South Florida Water Management District (SFWMD) issued a solicitation under the Northern Everglades Payment for Environmental Services (NE-PES) Program. ${ }^{1}$ The solicitation asked cattle ranchers to propose on-ranch water management practices to retain water and slow runoff toward Lake Okeechobee- a water retention service - or propose how they might remove nutrients from off-ranch water before that water reached the lake- a nutrient removal service. In responding to the solicitation, the ranchers requested the payment that would make them willing to provide these services during a 10-year contract period. The SFWMD reviewed the responses to the solicitation and, after negotiating with the ranchers, chose to enter into contracts with eight ranchers. A second solicitation was issued in winter 2013. Twenty proposals were submitted and a final selection of contracts is expected in late summer 2013.

Environmental services such as improved water quality, wildlife habitat, carbon sequestration, and hydrologic flow modification can be provided from working ranchlands. ${ }^{2}$ Payment for Environmental Services (PES) programs seek to increase the level of such services, above what would be provided by these lands in the future. Equally important, PES can support the financial viability of cattle ranching, a land use compatible with conservation objectives but one with low profit margins. For these reasons PES programs on ranchlands are advocated with increasing frequency. ${ }^{3}$ In fact, the NE-PES program is a unique example of an operating PES program built on market-like principles. The distinguishing feature that makes NE-PES market-like is that payments only are made if the services are provided. This makes the NE-PES different from programs that only pay a share of the cost for the installation of best management practices.

The link between realized services and the payment requires a monitoring protocol for documenting service provision. However, that monitoring protocol must be feasible to administer across large landscapes, given inevitable limits on the monitoring budget. Of course the protocol must satisfy the buyers that they are getting the services they pay for and assure the sellers that the services they provide are being fairly assessed. For this reason it is noteworthy that while the NE-PES payment only is made if the buyer believes that the service is provided, the monitoring protocol does not directly measure the service level. Therefore, before describing the NE-PES protocol we first introduce the collaborative process that led up to the NE-PES in order to explain how the SFWMD (buyer) and the rancher (sellers) agreed on a protocol that was not based on directly measuring the service. 


\section{Setting for the NE-PES}

The Northern Everglades begins south of Orlando, the site of the 67th Society for Range Management Annual Meeting, ${ }^{i}$ and includes the Kissimmee River, Lake Okeechobee, and adjacent coastal estuaries to the east and west. More than 100 years ago, public agencies and private landowners began to transform the land, building a vast canal and ditch network and a dike around Lake Okeechobee. Today, the hydrologic regime of the watershed, which is nearly flat with many seasonally flooded wetlands, is governed by hundreds of publicly managed flow-control structures and thousands of miles of canal and ditch networks on private land. This massive system that drained the land supported agricultural production and has accommodated a significant increase in human settlement. However, much of the area remains open range and today about one million acres (more than 30\% of the total watershed) includes improved and unimproved pasture, wetland, and woodlands.

The historic hydrologic modifications and land use changes fragmented wildlife habitat and accelerated the movement of water and nutrients from uplands into marshes and lakes, leading to increasing nutrient loads with associated algal blooms in Lake Okeechobee and extreme lake level fluctuations. When high lake levels threaten the dike, freshwater is released out of the lake through canals to the St. Lucie and Caloosahatchee estuaries. This nutrient-laden freshwater has caused harmful algal blooms and marine sea grass die offs and has weakened the populations of oysters and other marine life.

In recent decades an array of regulations, best management practice (BMP) cost-share programs and public investments in regional reservoirs, aquifer storage and recovery wells, and storm water treatment areas have been put in place to reverse these adverse environmental changes in the lake and in the estuaries. The SFWMD created the NE-PES program as a complement to these programs and projects.

\section{Origins and Design of the NE-PES}

The NE-PES program had its origins in the Florida Ranchlands Environmental Services Project (FRESP), a six-year collaboration that included ranchers, state and federal agencies (including the SFWMD), environmental groups, and researchers. ${ }^{4}$ FRESP collaborators had come together in 2005 around the consensus that ranchlands could provide flow regulation and nutrient removal services by making modifications to existing on-ranch water management structures and strategies. ${ }^{\text {ii }}$ The modifications were termed

i The 67th SRM Annual Meeting, From Dusty Trails to Waning Wetlands, will be held in Orlando, Florida, 8-13 February 2014. Join us there to learn more about Florida rangelands. For more information on the 2014 SRM Annual Meeting, see http://www.rangelands.org/events/.

ii The FRESP collaborators understood that Water Management Alternatives (WMAs) only could make a difference in the flow and nutrient loading at the system level if there were thousands of acres under contract. However, the PES program would of necessity start small and then need to grow to a scale where differences in the flows and nutri-

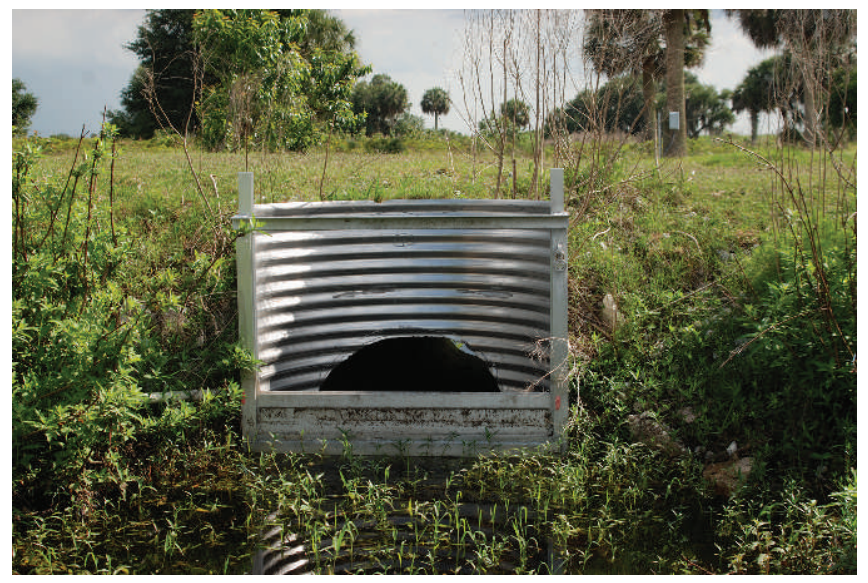

Figure 1. A culvert with a riser board installed to retain water. Note the padlock on the right is included as one element to ensure contract compliance. Photo courtesy of Elizabeth Boughton.

"Water Management Alternatives" (WMAs), defined as combinations of construction and management practices chosen by the landowner and implemented within a defined area of a working ranch. The group agreed that WMAs, if implemented across the watershed, could reduce nutrient loads coming to the lake, dampen harmful fluctuations in the lake's water levels, and reduce the need for harmful releases to the estuaries.

The FRESP collaborators set out to design a market-like program where the rancher would decide on the number, design, and operation of WMAs and the payment would be tied to the level of services provided. Rather than design a program first and then try to implement it, FRESP collaborators decided to implement on-ranch WMA pilot projects and come to agreement on design of the program based on what was learned by contracting, designing, constructing, permitting, and operating the pilot projects. The NE-PES definition of the service and the monitoring protocol emerged from this collaborative learning process.

\section{Defining the Services}

Throughout the FRESP pilot phase, collaborators worked to refine the service definitions in ways that were understood by the buyers and sellers and were measurable given real-world ranch conditions. The result was that the NE-PES program defined two types of WMAs for purposes of the solicitation. In responding to the solicitation, the rancher would specify which service (that is, type of WMA) that was being pro-

ent loads would become evident. During the FRESP process the collaborators participated in a limited system modeling effort that found significant reductions in flows to the Lake in high rainfall months when there was about 300,000 acre-feet of water retention. Other "back of the envelope" calculations found reductions in adverse releases to the estuaries at a similar scale. However, the program was launched without the need for or reference to these results. At the present time there are no plans for a system-wide assessment. 


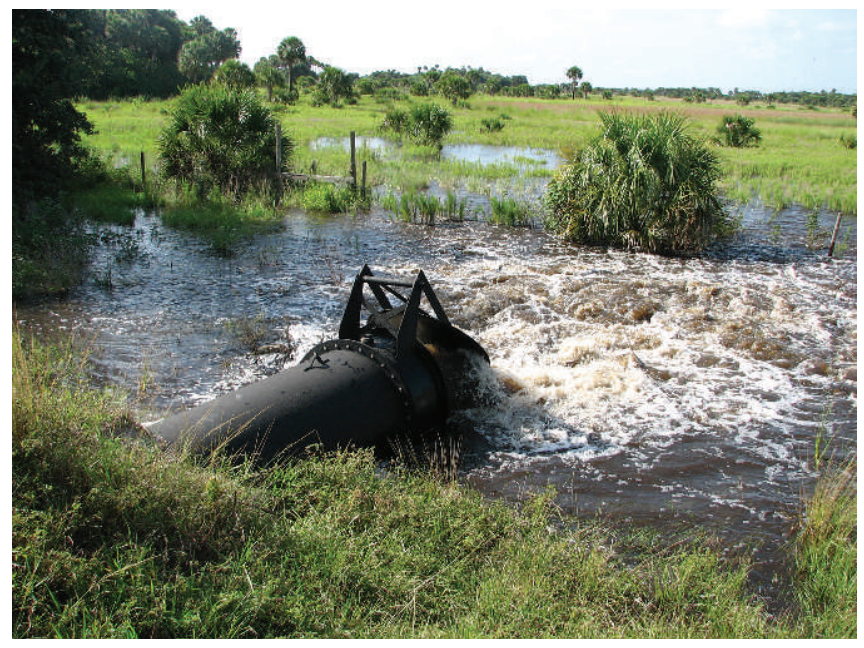

Figure 2. Water is pumped into a 2,500 acre marsh from a regional canal where nutrients are sequestered by natural processes. Photo courtesy of Earl Keel.

posed. A rancher is able to submit more than one WMA proposal, for the same service or for different services, on the same ranch but not on the same parcel.

Water retention WMAs hold back on-ranch storm water that would have flowed into the surface water drainage system. The service is produced by maximizing evapotranspiration (ET) and groundwater seepage. The specific service was defined as total acre-feet of water retention during a 12-month period. A simple example of a water retention WMA is a culvert riser board system (Fig. 1) in a rehydrated wetland.

A nutrient removal WMA diverts or pumps off-site water from a public canal or river onto the ranch WMA, and retains the water for a period of time (Figs. 2 and 3). During that time the biological, chemical, and physical process in the soils and vegetation remove, volatize, and sequester nutrients. The water is then returned with reduced nutrients to the canal or river. The specific service was defined as pounds of nutrient (phosphorus $[\mathrm{P}]$ or nitrogen $[\mathrm{N}]$ ) removed.

\section{From Measurement of Service to Contract Compliance}

The FRESP collaborators agreed that documentation of the services for payment must be credible to both the buyer and the seller. They also agreed that the effectiveness (i.e. greater accuracy and precision) from more measurements needed to be evaluated in relation to the increased cost of collecting, managing, and analyzing additional data and incorporating the information into a timely process for determining whether a payment should be made. However, even with this admonition to consider cost-effectiveness in whatever was measured, there still needed to be agreement on what measurement would be used to justify making the payment.

Initially the FRESP team expected to link the rancher's payment to measured acre-feet of water retention and pounds of nutrients retained each year from a given WMA. The pilot

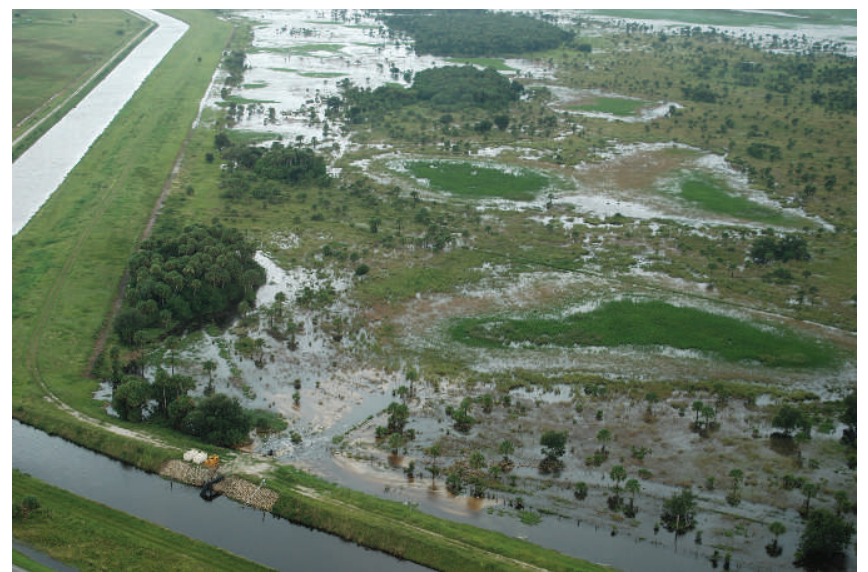

Figure 3. An aerial view of the Lykes West Waterhole marsh, a nutrient removal project, during a large tropical storm. Photo courtesy of Patrick Bohlen.

sites were instrumented to collect data that in turn could be used to make such measurements. The collaborators designed an analysis that would identify the minimum cost for instrumentation, data collection, and data analysis that also would give both buyer and seller confidence in the estimate of the service provided.

However, as this analysis was beginning both buyer and seller expressed concern that the services provided in any year would necessarily vary with annual rainfall. Water could not be retained if there was a dry year. Nutrient removal services would not be possible if pumps and diversions could not be operated because canal water levels did not reach a certain elevation. From the buyer's perspective, their budget requirements to honor contracts would fluctuate unpredictably with the weather, and there was no way the agencies could prepare budgets or secure additional funds to accommodate such fluctuations. Ranchers, as sellers, preferred a fixed annual income source to smooth out the more variable annual ranch income and cash flow.

The mutual preference of the buyer and seller, therefore, was for a contract that set a constant annual service payment over the life of the contract. This mutual preference had implications for documenting service provision. First, the level of services that would be the basis for the contract and the payment had to be agreed to before the WMA was implemented. This meant that the contract would be written using a model prediction of average annual water retention, or nutrient removal, during a 10-year period of rainfall record. A model was developed to predict water retention and a computational formula was used to predict nutrient removal. The predictions would be made using WMA site-specific conditions, e.g., size, soils, vegetation, topography, existing and proposed water management infrastructure (berms, pumps, height on riser boards in outfall ditches). In their proposals, ranchers identify the type of WMA and employ the specified prediction tool to make an estimate of average annual acrefeet retained or pounds removed. The payment would be a 
fixed annual service payment recognizing that in any one year a rancher might fall short of or exceed the service level commitment; however, over the life of the 10-year contract, the average service level would be provided.

Consider the example of a water retention WMA. A given WMA site might have an average annual water retention estimate of 1,000 acre-feet per year over a 10-year period of rainfall record. However, in any one year there was no expectation that the WMA site will retain 1,000 acre-feet of water. In a drought year the acre-feet retained would be less than the predicted annual average and in a wet year the measured acre-feet would exceed that annual average. However, there still was a need to demonstrate to the buyer that the rancher was providing the water retention service, subject to rainfall, as specified in the contract. iii

\section{Monitoring Protocol for Contract Compliance}

With the payment decoupled from the actual service provision there was no compelling reason to measure actual acre-feet water retained or pounds of $\mathrm{P}$ removed. The focus was now on finding a cost-effective way for documenting contract compliance. This meant assembling evidence that the operation and maintenance of the WMA was as specified in the contract.

For the water retention service this meant documenting a relationship between rainfall and water retained. To that end, a requirement of the NE-PES contract was that riser board structures were bolted at a specified elevation (note padlocked weir [upper right] in Fig. 1) providing one measure of assurance that the contract was being honored. In addition, pressure transducers were installed at the WMA site to record water elevation inside the WMA at each discharge location. These were paired with tip buckets to record rainfall at the WMA. The expectation was that water elevation should rise with rainfall up to the locked board elevation, at which time it would flow out of the WMA. If water stages responded to rainfall, it could be concluded that the WMA was retaining water (Fig. 4). If water stages did not respond to rainfall, that was an indication that the water retention service was not being provided or that monitoring equipment was not functioning properly (Fig. 5).

The nutrient removal service required pumping water from a public water body (river or canal) onto the ranch, blocking outfall ditches with boards to retain the water long enough for the nutrients to be removed by slowing the flow of water back to the public water course. Contract compliance monitoring involved using pump records to assure that the water, in the volumes proposed, was being diverted as called for by the contract. To assure that the pumped water was retained, the presence and height of boards at outfall structures would be checked as was done for the water retention WMA.

\footnotetext{
iii The nutrient removal service also was related to rainfall. To protect the interests of downstream water users, pumping water from a public water body (river or canal) onto the ranch was only allowed when the stage height in the river or canal reached a specified level.
}

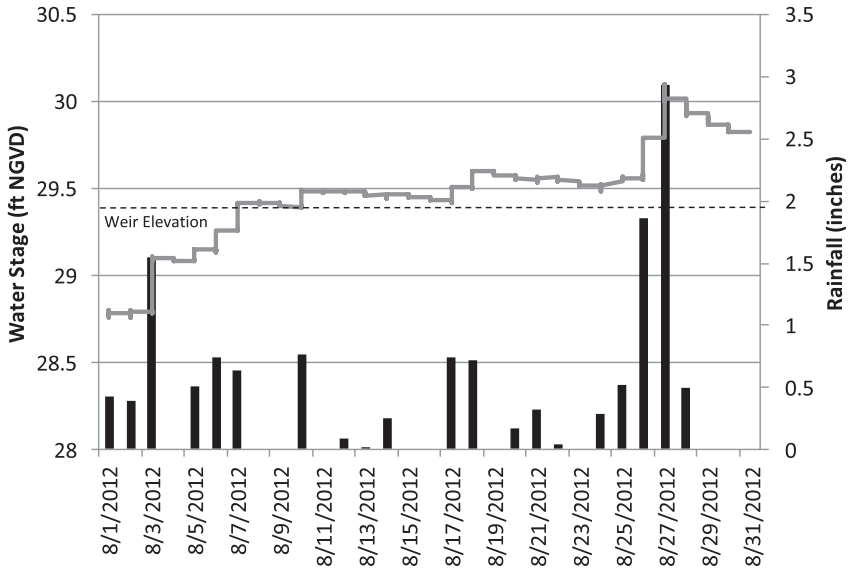

Figure 4. Water stage (gray line) responds positively to rainfall (solid bars) at one of the NE-PES WMA monitoring sites. The pressure transducer records water levels every 15 minutes. If water stage did not respond logically to rainfall, that would be an indication the WMA was not functioning properly.

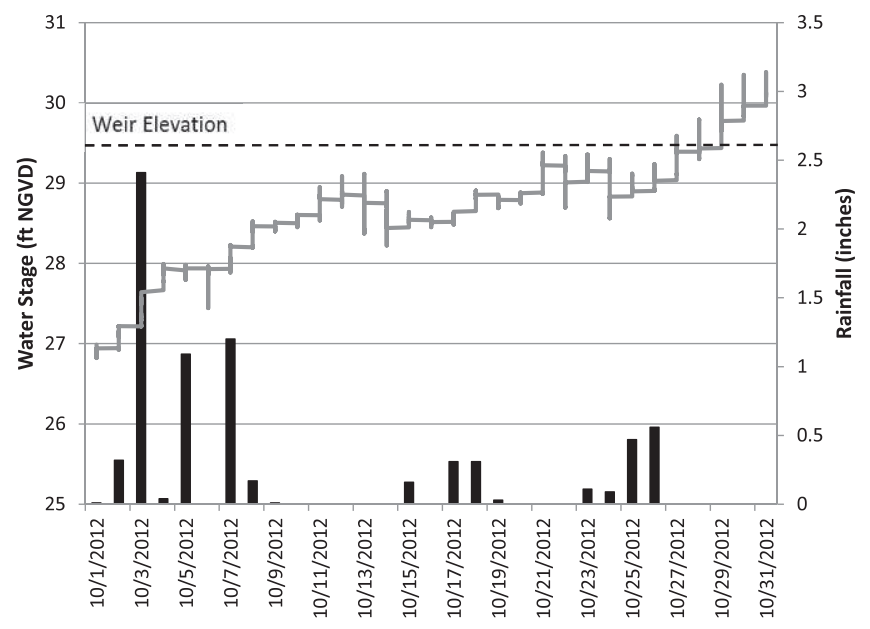

Figure 5. The pressure transducer is recording increasing water stages without much rainfall. This indicates the pressure transducer is "drifting" and should be replaced or calibrated.

Data also were collected from pressure transducers at outfall locations, as with the water retention WMAs, to assure that there was a reasonable relationship between the pumped water plus the rainfall volumes and the changes in the stage heights inside the WMA. ${ }^{\text {iv }}$

To implement the monitoring protocol, the SFWMD contracted with a third-party entity (referred to as the field team) to be responsible for verifying contract compliance for the eight water retention service contracts awarded under the first solicitation. The field team is responsible for installing specified monitoring equipment at each WMA site (Fig. 6); making monthly site visits; operating and maintaining the

iv No nutrient removal projects were chosen in the first solicitation. Therefore this protocol for contract compliance has not been field tested. 


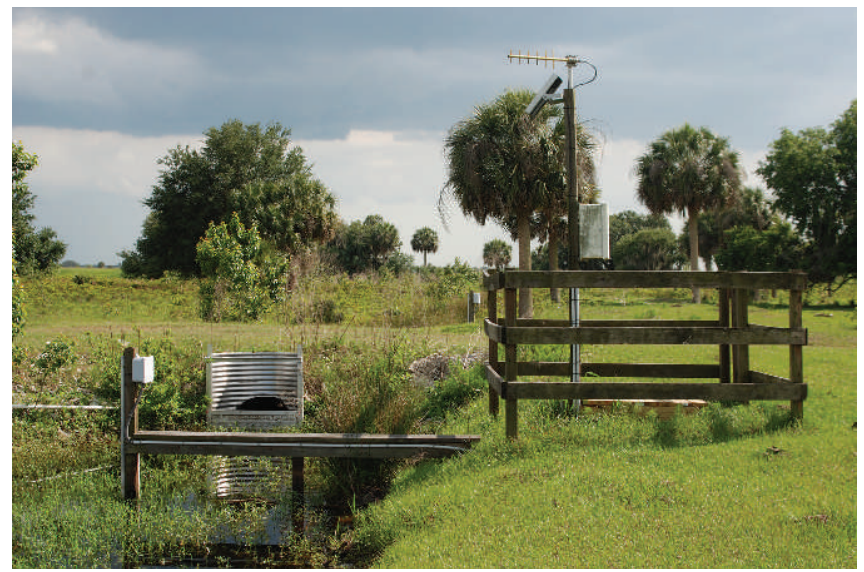

Figure 6. One example of a NE-PES monitoring site. Water stage is recorded every 15 minutes by a pressure transducer and the data is stored in a datalogger in a waterproof box mounted to the wooden post. A solar panel powers the station. A rain tipping bucket is at a nearby monitoring station. Photo courtesy of Elizabeth Boughton.

equipment; collecting, managing, and analyzing data from the sites; and preparing reports. The field team conducts monthly site visits to verify that structures are bolted at the contracted elevation, downloads water stage and rainfall data, and checks on the condition of the WMA. During these site visits, the rancher provides a form that verifies that the WMA site has been operated and maintained as specified in the contract. After collecting and transferring the data to an electronic format, the field team processes the data through a standard $\mathrm{QA} / \mathrm{QC}$ procedure, ensuring that stage inside the WMA varies logically with rainfall and pumped water inputs. These data are compiled in a monthly report which is submitted to the rancher for review, and then submitted to the SFWMD. At the anniversary of the certification of the WMA, the rancher compiles all 12 monthly reports into an annual report and submits it to the SFWMD to receive the annual service payment.

\section{Conclusion}

A market-like program requires verification that a service is being provided before a payment is made. However, to be cost-effective, the verification protocol should only be as detailed as needed to assure the buyer that they are getting the contracted service. In the NE-PES program, the design called for a monitoring protocol that showed that water retention or nutrient removal service was being provided, but that did not require exact measurement of the service level. As a result, the current contract compliance protocol is a (relatively) low-cost, transparent protocol that is feasible to administer in the real-world conditions of ranchers in the Northern Everglades.

The current protocols were developed and refined by working with a relatively small number of rancher participants. As the program expands, both in the number of contracts and geographically through the Northern Everglades, the documentation protocol will need to evolve to further increase its cost-effectiveness. Several modifications that could both reduce costs and improve data collection, management, and analysis efficiency include: 1) transition to paperless data collection through the use of laptop or electronic pads in the field to record and download data; 2) begin data transmission through cellular modems to reduce the number of site visits, saving on travel costs while being able to access data in realtime, verify equipment is working properly, and check the quality of the data; and 3) reduce the frequency of site visits tying visits to rainfall conditions at the site, or only visiting the site when there are anomalies in the transmitted data.

\section{Acknowledgements}

We would like to acknowledge collaboration partners who have contributed to the FRESP and our understanding of PES programs: ranchers J. Alderman, J. Collins, C. Lightsey, G. Lollis, J. Payne, C. Syfrett, W. Williamson, and J. Wohl; scientists P. Bohlen (UCF), M. Clark, A. Guzha, and S. Shukla (UF-IFAS), and H. Swain (Archbold Biological Station); agency personnel R. Budell (FDACS), F. Nearhoof (FDEP), B. Whalen (SFWMD), and G. Hendricks (USDA NRCS). We would like to acknowledge members of the NE-PES field team for their technical assistance in designing and implementing the NE-PES monitoring system: S. Hollingsed, E. Keel, R. Mesmer, G. Ragosta, and K. Ewing (MAERC/Archbold). Opinions expressed are those of the authors and not necessarily the funders or other collaboration partners. This paper is contribution No. 148 from the MacArthur Agro-ecology Research Center (MAERC).

\section{References}

1. Lynch, S. and L. Shabman. 2011. Designing a payment for environmental services program for the northern Everglades. National Wetlands Nerwsletter 33:12-15.

2. Bohlen, P. J., S. Lynch, L. Shabman, M. Clark, S. Shukla, and H. Swain. Paying for environmental services from agricultural lands: an example from the northern Everglades. Frontiers in Ecology and the Environment 7:46-55.

3. Goldstein, J. H., C. K. Presnall, L. Lopez-Hoffman, G. P. Nabhan, R. L. Knight, G. B. Ruyle, and T. P. Toombs. 2011. Beef and beyond: paying for ecosystem services on western US Rangelands. Rangelands 33: 4-12.

4. Florida Ranchlands Environmental Services Project. Available at: www.fresp.org. Accessed 15 July 2013.

Authors are Resident Scholar, Resources for the Future, Washington DC 20036, USA, Shabman@rff.org (Shabman); Director, Agriculture, World Wildlife Fund, Washington, DC 20090, USA (Lynch); and Program Director of Agro-ecology and Research Biologist, MacArthur Agro-ecology Research Center, Lake Placid, FL 33852, USA (Boughton). Funding for the FRESP from USDA NRCS Conservation Innovation Grant, SFWMD, FDACS, and the W.K Kellogg Foundation is greatly appreciated. 